Jakub Bożydar Wiśniewski

ORCID: 0000-0003-4126-1867

Instytut Edukacji Ekonomicznej im. Ludwiga von Misesa

jakub@cantab.net

\title{
Austrian welfare economics: A reply to Wysocki and Megger
}

Date of submission: 14.09.2019; date of acceptance: 15.10.2019

JEL Classification: B41, B53, D60, D63, P14

Keywords: welfare economics, Austrian economics, Rothbard, property rights

\begin{abstract}
Austrian welfare economics: A reply to Wysocki and Megger

In their article published in a recent issue of this journal, Wysocki and Megger (2019) attempt to undermine Rothbard's welfare theory as articulated in his classic essay on the subject (2008). More specifically, they suggest that the theory in question generates some fatally counterintuitive conclusions and relies on viciously circular arguments. In this response, my aim is to demonstrate that while the article under consideration raises some interesting points, the rather monumental task that its authors set themselves - that is, the task of dismantling the whole of Austro-Rothbardian welfare economics - results in failure.
\end{abstract}

Wysocki and Megger (2019) claim that Rothbard's welfare theory, as presented in his classic essay on the subject (2008), fails to prove its intended conclusion. More specifically, they suggest that the theory in question generates some fatally counterintuitive results and relies on viciously circular arguments. In this response, I argue that the objections raised by the abovementioned authors miss their mark by failing to grasp the praxeological essence of certain crucial points that constitute Rothbard's analytical edifice, which is grounded in the broader insights of the Austrian School into the nature of human action, the market process and transactional efficiency.

According to Rothbard, since embracing the subjectivist theory of value makes interpersonal comparisons of utility impossible, only voluntary interactions between 
purposive agents can be justifiably regarded as increasing social utility. Thus, the free market, understood as the embodiment of large-scale social cooperation based exclusively on the principles of contract and consent, emerges as the only environment capable of impacting social welfare in an unambiguously positive manner. By the same token, says Rothbard, every coercive intervention into the free market system necessarily diminishes social welfare by reducing the extent to which peaceful agents can enter into mutually beneficial relationships.

Wysocki and Megger direct two specific counterarguments against the line of reasoning sketched above. First, they compare two hypothetical transactions that are seemingly identical in terms of their Pareto-superiority, even though one of them is purely voluntary, while the other is based on a threat of violence. More specifically, they compare a scenario in which a tax collector extorts a certain sum of money from his victim with a scenario in which a potential competitor is willing to be bought off for the same amount of money. Subsequently, they argue that since both of these scenarios involve transactions whose final result is the maintenance of the status quo, even though one of them is voluntary while the other is coercive, voluntariness cannot be regarded as the essential characteristic that separates Pareto-superior transactions from Pareto-inferior ones.

There are numerous reasons, however, to view the abovementioned two cases as significantly dissimilar. Most importantly, the threat issued by the tax collector disrupts the free market system - that is, the sum total of voluntary interpersonal interactions aimed at mutual welfare maximization (Salerno, 1993, 130). Thus, paying the tax collector off does not preserve the pre-existing status quo, but rather, first, deprives the payer of the money that he originally possessed, thus leaving him worse off, and, second, testifies to the fact that he now inhabits an interventionist, zero-sum world instead of the voluntarist, positive-sum world that he inhabited before the tax collector showed up. Paying off the potential business competitor, on the other hand, is a purely contractual interaction, which, instead of preserving the status quo, establishes a more favorable business environment as far as the payer is concerned.

In addition, it should be noted that in the latter scenario the "blackmailee," unlike the victim of the tax collector from the former scenario, is under no obligation to take up the "offer" presented to him. He might as well come to the conclusion that if the potential competitor is willing to be bought off before even starting to establish his business, he is presumably a pretty feeble businessman, who is unlikely to upset the existing market conditions. Even if, upon refusing his offer, the "blackmailee" were to find out that the "blackmailer" is actually a fully competent businessman, that would not necessarily decrease the former's welfare, since in the market system competitors can learn from each other's successes, obtaining information crucial to the development of their respective entrepreneurial visions (Hayek, 2002). In sum, to characterize the two cases under consideration as identical in terms of their outcomes is a logically inadmissible proposition, which 
ignores the essential praxeological differences between responding to a business offer and acting under the threat of violence.

It might be suggested in reply, as Wysocki and Megger in fact do, that the above defense of Rothbard's welfare theory "plays fast and loose with normalcy (with a normal or expected state of affairs serving as a benchmark for ordinal utility comparisons)" (Wysocki and Megger, 2019, 78). This, however, is not the case, since, as indicated in the previous paragraphs, preserving one's liberty in an extortionist system and maintaining one's market niche in a competitive business environment are most definitely not identical benchmarks as far as praxeologically understood Pareto-efficiency is concerned. Operating in the context of the former requires incurring additional opportunity costs just in order to retain one's ability to enter into voluntary transactions and raise one's welfare above the initial baseline. Operating in the context of the latter requires no such thing - as mentioned earlier, the emergence of an additional competitor need not be construed as a downward departure from the initial baseline of one's welfare. In other words, there is a fundamental praxeological asymmetry between responding to voluntary business offers (of whatever nature) and responding to coercive "offers one can't refuse" (Wiśniewski, 2013). Thus, there is also a fundamental asymmetry between the corresponding starting points serving as benchmarks for intrapersonal utility comparisons.

This conclusion leads us to the second counterargument formulated by Wysocki and Megger. As they see things, by identifying voluntariness as the essential feature of Pareto-superior interactions and by defining the free market as the sum total of voluntary transactions taking place in society, Rothbard makes his welfare argument for the free market viciously circular. In fact, however, Rothbard's argument follows a clear line of deductive, causal-realist reasoning. To wit, rather than arbitrarily defining Pareto-superiority as the result of voluntary interactions, Rothbard derives such a definition from the action axiom and its subjectivist implications, including the impossibility of making interpersonal utility comparisons. Consequently, his definition of the free market as the sum total of voluntary transactions is likewise not arbitrary, but deductively justified, grounded in the nature of catallactic development and in the fundamental distinction between the economic and the political means (Oppenheimer, 1922). As such, it is perfectly consistent with the description of the free market offered by his mentor, Ludwig von Mises, who described the institution in question as "the total complex of the mutual relations created by [...] concerted actions" aimed at "cooperation and coadjuvancy with others for the attainment of definite singular ends" (1996, 143).

Thus, far from being viciously circular or tautological, Rothbard's argument is constructive and cogent: it proceeds from a praxeologically sound reflection on the nature of human action and culminates in an equally sound conclusion regarding its catallactic ramifications. 
In sum, both objections raised by Wysocki and Megger, at least as presented in their article, fall short of their ambitions. Perhaps they could become more compelling if, instead of adopting a purely negative approach, they were to suggest concrete improvements in the criticized position. For the time being, however, they are clearly too interpretively cursory and argumentatively inchoate to deal adequately with an issue as big as the total edifice of Austro-Rothbardian welfare theory.

\section{References}

Hayek, F. A. (2002). Competition as a discovery procedure. Quarterly Journal of Austrian Economics, 5(3), 9-23.

Mises, L. von (1996) [1949]. Human Action. 4th ed., revised. San Francisco: Fox and Wilkes.

Oppenheimer, F. (1922) [1914]. The State. New York: B. W. Huebsch.

Rothbard, M. N. (2008) [1956]. Toward a reconstruction of utility and welfare economics. In M. Sennholz (ed.), On Freedom and Free Enterprise: Essays in Honor of Ludwig von Mises (224-262). Auburn, AL: Ludwig von Mises Institute.

Salerno, J. T. (1993). Mises and Hayek dehomogenized. Review of Austrian Economics, 6(2), 113-146.

Wiśniewski, J. B. (2013). Non-excludability, externalities, and entrepreneurship — an overview of the Austrian theory of common goods. Journal of Prices \& Markets, 1(1), 57-68.

Wysocki, I., Megger, D. (2019). Austrian welfare theory: A critical approach. Ekonomia - Wroclaw Economic Review, 25(1), 73-80. 